\title{
Erratum to: Experimentally induced deep cervical muscle pain distorts head on trunk orientation
}

\author{
Eva-Maj Malmström • Hans Westergren • \\ Per-Anders Fransson • Mikael Karlberg • \\ Måns Magnusson
}

Published online: 1 August 2013

(c) Springer-Verlag Berlin Heidelberg 2013

\section{Erratum to: Eur J Appl Physiol}

DOI 10.1007/s00421-013-2683-y

Unfortunately, there is a swap in given and family names of the complete author group in the online published article.

The correct author group should read as given below.

Eva-Maj Malmström · Hans Westergren ·

Per-Anders Fransson · Mikael Karlberg .

Måns Magnusson

The online version of the original article can be found under doi:10.1007/s00421-013-2683-y.

E.-M. Malmström $(\bowtie) \cdot H$. Westergren Unit for Specialized Pain Rehabilitation, Department of Rehabilitation Medicine,

Skåne University Hospital, 22185 Lund, Sweden

e-mail: eva-maj.malmstrom@med.lu.se;

evamaj.malmstrom@skane.se

E.-M. Malmström · P.-A. Fransson · M. Karlberg ·

M. Magnusson

Department of Otorhinolaryngology, Clinical Sciences,

Lund University, 22185 Lund, Sweden 